\title{
Epidemiology Distribution of 48 Diagnosed COVID-19 Cases in Bangladesh: A Descriptive Study
}

\author{
Article by Irin Hossain ${ }^{1}$, Ashekur Rahman Mullick ${ }^{2}$, Manzurul Haque Khan ${ }^{3}$, Sk Akhtar \\ Ahmad $^{4}$, Shafiur Rahman ${ }^{5}$, M M Aktaruzzaman 6 \\ 1,3,5 Department of Occupational and Environmental Health, National Institute of Preventive \\ and Social Medicine, Dhaka, Bangladesh \\ ${ }^{2}$ Department of Surgery, Delta Medical College and Hospital, Dhaka, Bangladesh \\ ${ }^{4}$ Department of Occupational and Environmental Health, Bangladesh University of Health \\ Sciences, Dhaka, Bangladesh \\ ${ }^{3}$ Scientific Section, Directorate General of Health Services, Dhaka, Bangladesh \\ E-mail: irin.hossain@gmail.com ${ }^{1}$, ashekmullick@gmail.com ${ }^{2}$
}

\begin{abstract}
In 8 March, 2020 COVID-19 was first confirmed in Bangladesh. We aimed to clarify the epidemiological distribution of first forty-eight confirmed COVID-19 cases in Bangladesh till 28 March, 2020. It was a retrospective descriptive study in Bangladesh from 8 March, 2020 to 28 March, 2020 on the basis of official press briefing of IEDCR on behalf of Ministry of Health in Bangladesh, different newspapers and online news portals. Among forty-eight cases, majorities (60\%) were male and about $17 \%$ cases were unidentified. About $46 \%$ cases were within 21-40 years of age. About $4 \%$ cases were from below 10 years of age and about $15 \%$ were from more than 60 years of age. About $12 \%$ cases age was unidentified. Mortality rate were also high in old age group. Total $11 \%$ cases were died from this COVID-19 and among them $40 \%$ were 70 years old. About $31 \%$ had travelling history from abroad. In case of 7\% cases, their travelling countries were unidentified. Most of them (35\%) were from Dhaka city. About 24\% cases residence were not identified. About 33\% of these 48 cases, they were exposed by their family members or community transmission. Only $10 \%$ cases were from health service and among them 60\% were doctors/physicians and $40 \%$ were nurses. Majority of them (58\%) were still remain in hospital or treatment purpose. About $11 \%$ were died and most of them were more than 65 years of age. COVID-19 is more dangerous in elderly male cases and mortality is also high in this group. Community gathering places like capital city of Bangladesh had high rate of COVID19 occurrences. Direct transmission rate was higher rather than community/family transmission till to date.
\end{abstract}

Keywords: Epidemiology, COVID-19, Diagnosed case.

\section{Introduction}

The corona virus belongs to large family of enveloped RNA virus and causes an infectious disease named coronavirus disease or COVID-19. The COVID-19 virus spreads primarily through droplets of saliva or discharge from the nose when an infected person coughs or sneezes. It may cause various symptoms like high rise of temperature, difficulty in respiration including lung infection and pneumonia like symptoms. On 29 December, 2019 The World Health Organizations (WHO) addressed lower respiratory tract affecting coronavirus as 2019 novel coronavirus which was taken place in Wuhan, China. Later, it named as severe acute respiratory syndrome coronavirus- 2 or simply SARS-Cov-2. It is thought that initially the virus had been transmitted from animal to humans. Subsequently the virus had travelled around the globe, and ultimately human-to-human transmission continues to be reported from different parts of the world. ${ }^{1-3}$ Outbreaks in different countries prompted the Ministry of Health and Family Welfare (MoHFW) Bangladesh to equip its PCR lab at IEDCR (Institute of Epidemiology, Disease Control and Research) for testing samples from suspected COVID-19 cases for 2019-nCov. Till 28 March, 2020, 176 countries including Bangladesh, have reported total 597,335 confirmed cases of 
COVID-19, leading 27,365 deaths over the world. In Bangladesh, first case of COVID-19 was declared on 8 March, 2020 after testing through RT-PCR on 7 March, 2020. Since then till 28 March total forty-eight confirmed case including fifteen recovery and five deaths. ${ }^{4}$

\section{Materials and Methods}

\section{Study Design}

It was a retrospective descriptive study of fortyeight confirmed COVID-19 cases in Bangladesh from 8 March, 2020 to 28 March, 2020 on the basis of official press briefing of IEDCR on behalf of Ministry of Health in Bangladesh, different newspapers and online news portals.

\section{Study population}

First forty-eight confirmed COVID-19 cases in Bangladesh till 28 March, 2020.

\section{Study period}

From 8 March, 2020 to 28 March, 2020.

\section{Selection criteria}

Study population was selected after confirming positive result of COVID-19 by Real-Time PCR (RT-PCR) and this was done in single test center in Bangladesh, named IEDCR (Institute of Epidemiology Disease Control and Research).

\section{Data collection technique}

We gathered epidemiological, demographical and outcome data of those forty-eight confirmed COVID-19 cases from official press briefing of IEDCR on behalf of Ministry of Health in Bangladesh. News and information related to COVID-19 in Bangladesh from various newspapers and online news portals were also reviewed.

\section{Analysis procedure}

We extracted all the data from the case reporting system, and removed the personally identifiable information of all cases during the analysis to protect personal privacy. If a patient was engaged in any form of work in a medical institution, the occupational variables are classified as health-care provider (that is, this category includes not only doctors and nurses).

If the patient had recently lived in abroad, or had traveled. If people have close contact, they are classified as having travelling history. This data analysis relates to information collected from 8
March, 2020 to 28 March, 2020 in relation to outbreak handling of COVID-19 epidemic situation in Bangladesh.

\section{Results}

Total forty-eight confirmed cases of COVID-19 were obtained for this study. Diagnosis was confirmed by RT PCR. Among forty-eight cases, majorities $(60 \%)$ were male and $(23 \%)$ were female. About $17 \%$ cases were unidentified (Figure 4). About $46 \%$ cases were within 21-40 years of age. Extreme age variation was also present. About $4 \%$ cases were from below 10 years of age and about $15 \%$ were from more than 60 years of age. About 12\% cases age was unidentified. Mortality rate were also high in old age group. Total $11 \%$ cases were died from this COVID-19 and among them $40 \%$ were 70 years old and $20 \%$ were 73 years, 69 years and 65 years old (Figure 2). About 31\% had travelling history from abroad and among them 39\% came from Italy and 13\% came from the USA and other European countries. About 7\% came from India, Kuwait, Bahrain and Saudi Arabia. In case of 7\% cases, their travelling countries were unidentified (Figure 8). According to the distribution of their residence, most of them (35\%) were from Dhaka city. About 21\% from Madaripur and 6\% from Narayanganj. About $24 \%$ cases residence were not identified (Figure 5). About 33\% of these 48 cases, they were exposed by their family members or community transmission (Figure 10). Most of the cases $(90 \%)$ didn't belong to health care services. Only $10 \%$ cases were from health service and among them $60 \%$ were doctors/physicians and $40 \%$ were nurses (Figure 9). Majority of them $(58 \%)$ were still remain in hospital or treatment purpose, $31 \%$ were discharged after recovery and findings 2 consecutive negative sets of result of nasopharyngeal and throat swabs collected $\geq 24$ hours apart from a patient with COVID-19. About $11 \%$ were died from this disease and most of them were more than 65 years of age (Figure 7).

\section{Discussion}

COVID-19 is more dangerous in elderly male cases and mortality is also high in this group as most of them were already sufferer from different type of comorbidity which decreased their immunity level and smoking habit was much common in male group which already diminished their normal lung functions and stimulated COVID-19 to affect the respiratory system easily. 
Community gathering places like capital city of Bangladesh had high rate of COVID-19 occurrences. Direct transmission rate was higher rather than community/family transmission till to date and majority of them also didn't have any travelling history at all, so chance of direct transmission of COVID-19 was much higher than community transmission. In Wuhan, China COVID-19 was predominant in elderly male group also. Recovery rate from COVID-19 was almost equal in between Bangladesh and China. ${ }^{3}$

Figure 3 showed the gradual increase of confirmed case over time and also death due to disease. The time duration between confirmation of disease and death was near about twelve days in Bangladesh though those two cases were not same but it gave a clear idea about incubation period of COVID-19 which was about fourteen days and this time limit is very much important for quarantine process. Figure 01 showed about the total number of home quarantine and also the total number of completed home quarantine. Number of quarantines was much higher around Dhaka city as most of earning youth group with their family live in Dhaka for their job purpose. It leads to aggravate the community transmission.

\section{Conclusion and Recommendations}

COVID-19 is more dangerous in elderly male cases and mortality is also high in this group. Community gathering places like capital city of Bangladesh had high rate of COVID-19 occurrences. Direct transmission rate was higher rather than community/family transmission till to date. Quarantine does not work if the population is insensitive. Safety of healthcare workers is of prime importance now. All doctors should be armed with all out personal protective equipment (PPE) immediately. Quarantine enforcement should be the responsibility of public administration and law enforcers. Ministry of health should hand over this responsibility to relevant people. COVID-19 outbreak is a public health emergency of international concern. Detecting infection is the key to preventing spread. Priorities for the combat against the COVID-19 Pandemic includes: protecting health workers, engaging communities to protect those at highest risk of severe disease (e.g., older adults and those with medical comorbidities), and supporting vulnerable communities in containing infection.

Screening for international travelers especially those from areas with ongoing transmission of COVID-19 virus to identify individuals with fever, cough, or potential high-risk exposure. Quarantine is a must for such individual's institution quarantine for those with fever and supervised strict home quarantine for those without fever. Everyone returning from abroad should be convinced that even if they were apparently healthy, they could be carrying the COVID-19 virus which they could spread to their dear ones unless they were cautious. Any one postponing quarantine or ignoring quarantine request may be considered as enemy of the society and dealt with accordingly. Recently Government gave permission for performing RT-PCR for detecting COVID-19 in some institutions followed by IEDCR (Table 1). This could help us in detecting COVID-19 as early as possible and thus would help combatting this pandemic disease. 


\section{Figures and tables}

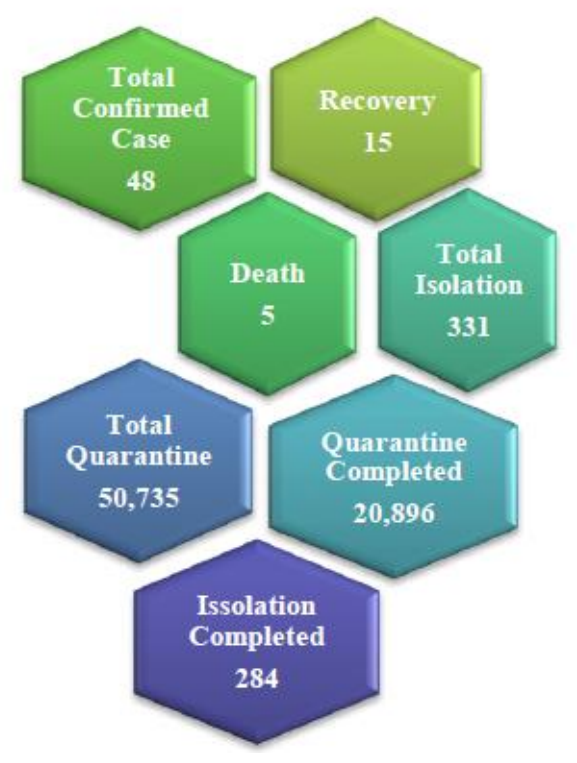

Figure 1. Overall scenario of COVID-19 in Bangladesh up-to 28 March, $2020^{5}$

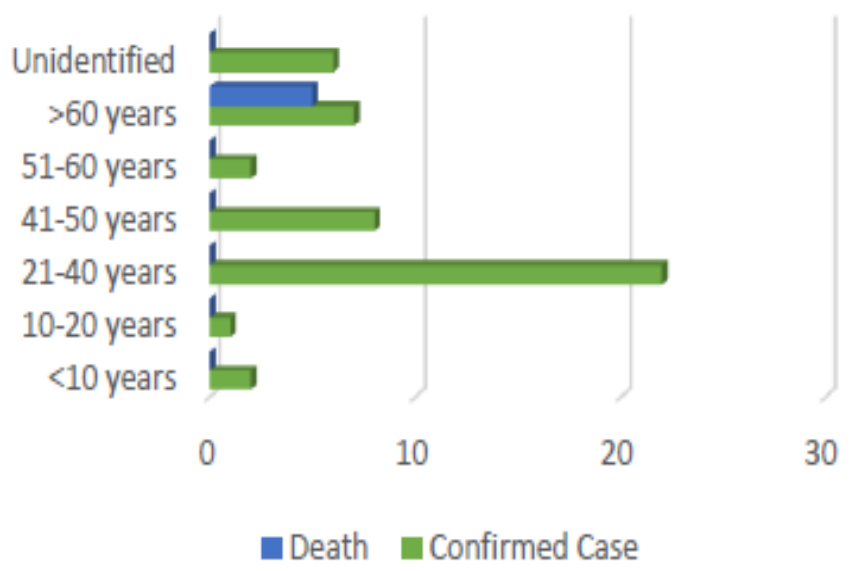

Figure 2. COVID-19 Cases and Deaths by Age ${ }^{1-14}$

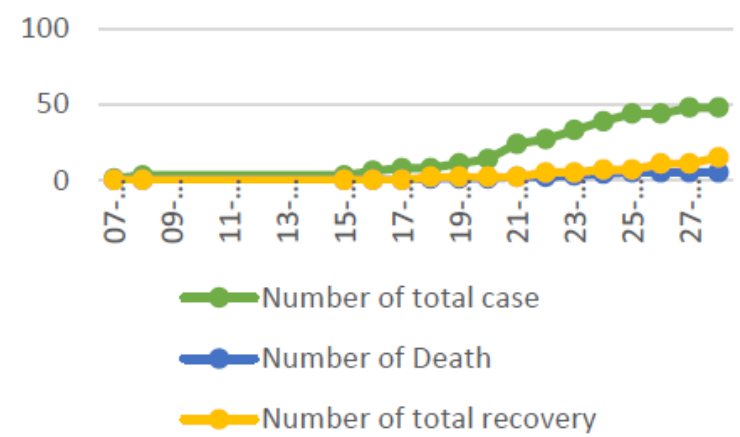

Figure 3. Number of total cases, total recovery and total death over time $e^{1-14}$ 


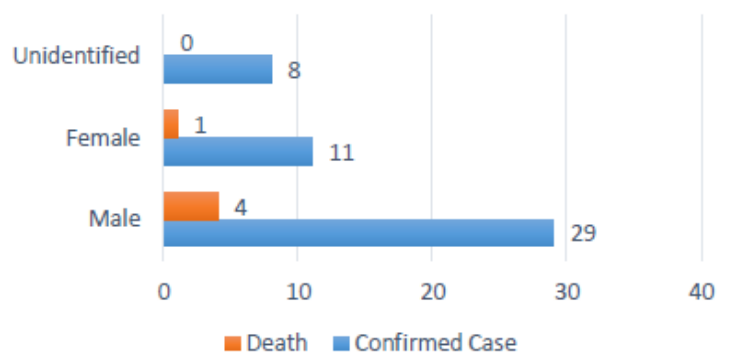

Figure 4. COVID-19 confirmed cases and death by gender1-14

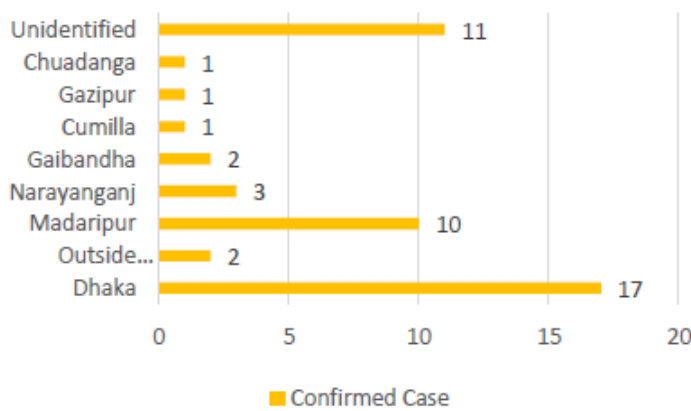

Figure 5. District wise Distribution of Confirmed Case1-14

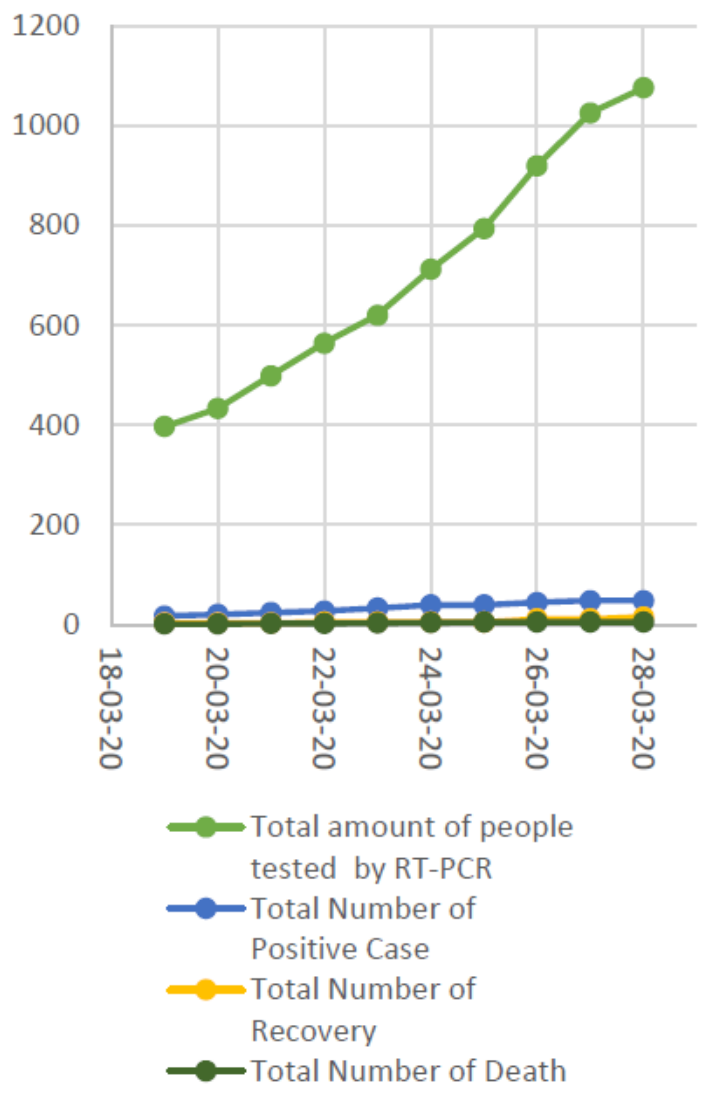

Figure 6. Confirmation and Outcome of COVID-191-14 


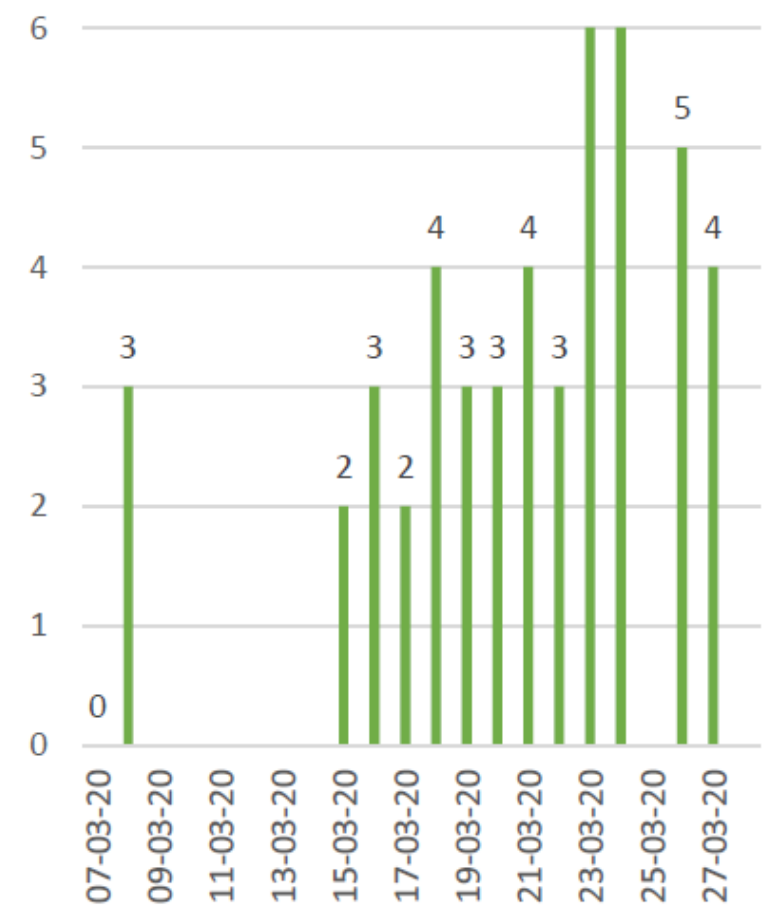

Figure 7. Frequency Distribution of Confirmed Case1-14

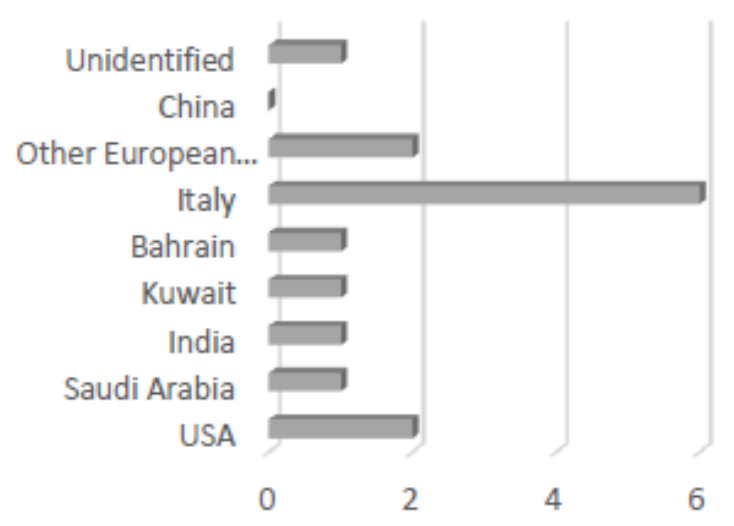

Figure 8. Confirmed cases by Travelling Countries ${ }^{1-14}$

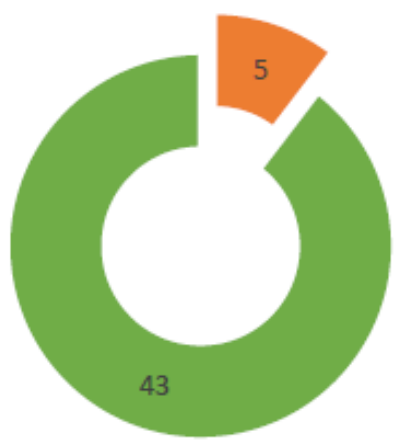

- Health care workers - Non health care workers 
Figure 9. Confirmed Case by profession (Health related) $)^{1-14}$

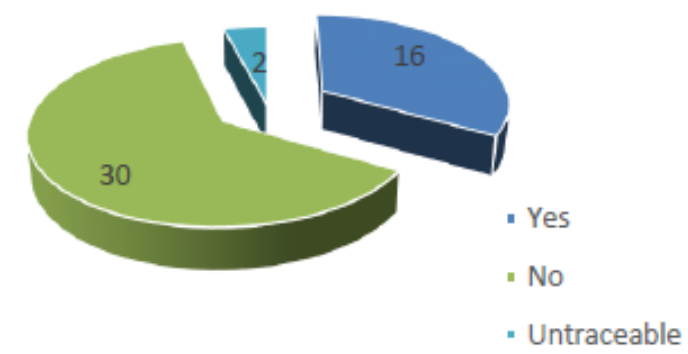

Figure 10. Confirmed cases according to family/community relation to expossure ${ }^{1-14}$

Table 1: Permitted Institution for performing RT-PCR in Bangladesh since 28 March, 2020

\begin{tabular}{|l|l|}
\hline Inside Dhaka & Outside Dhaka \\
\hline IEDCR & $\begin{array}{l}\text { Mymensingh Medical } \\
\text { College and Hospital }\end{array}$ \\
\hline $\begin{array}{l}\text { Dhaka Shishu (Children) } \\
\text { Hospital }\end{array}$ & $\begin{array}{l}\text { Rajshahi Medical } \\
\text { College and Hospital }\end{array}$ \\
\hline $\begin{array}{l}\text { Dhaka Medical College and } \\
\text { Hospital }\end{array}$ & $\begin{array}{l}\text { Khulna Medical College } \\
\text { and Hospital }\end{array}$ \\
\hline $\begin{array}{l}\text { Institute of Public Health } \\
\text { (IPH) }\end{array}$ & $\begin{array}{l}\text { Rangpur Medical College } \\
\text { and Hospital }\end{array}$ \\
\hline $\begin{array}{l}\text { Sir Salimullah Medical } \\
\text { College and Hospital }\end{array}$ & $\begin{array}{l}\text { Bangladesh Institute of } \\
\text { Tropical and Infectious } \\
\text { Diseases }\end{array}$ \\
\hline ICDDR, B & \multicolumn{2}{|l}{} \\
\hline
\end{tabular}

\section{References}

[1]. Lu H, Stratton CW, Tang YW. Outbreak of pneumonia of unknown etiology in Wuhan China: the mystery and the miracle [published January 16, 2020]. J Med Virol. 2020.

doi:10.1002/jmv.25678 PubMed Google Scholar [2]. World Health Organization. 2020. Coronavirus. https://www.who.int/health

topics/coronavirus\#tab=tab_1. Accessed on $27 \mathrm{March}$, 2020

[3]. Chen N, Zhou M, Dong X, Qu J, Gong F, Han Y, et al. Epidemiological and clinical characteristics of 99 cases of 2019 novel coronavirus pneumonia in Wuhan, China: a descriptive study. Lancet [Internet]. 2020;395(10223):507-13.

http://dx.doi.org/10.1016/S0140-6736(20)30211-7

Dashboard of Directorate General of Health Services (DGHS), The Government Republic of Bangladesh. 2020.

https://www.dghs.gov.bd/index.php/bd/. Accessed on 26 March, 2020

[4]. Coronavirus

COVID-19.

2020 .

http://corona.gov.bd/. Accessed on 28 March, 2020
[5]. Coronavirus COVID-19 Dashboard. 2020. http://103.247.238.81/webportal/pages/covid19.php. Accessed on 28 March, 2020

[6]. Bangladesh confirms first three coronavirus cases. Somoy English Desk. 2020 March 16:20. Available at: https://en.somoynews.tv/5897/news/Bangladeshconfirms-first-three-coronavirus-cases

[7]. 2 more coronavirus cases detected in Bangladesh: Health Minister. Somoy English Desk. 2020 March 22:17.

https://en.somoynews.tv/6115/news/2-morecoronavirus-cases-detected-in-Bangladesh-HealthMinister

[8]. 2,314 in quarantine, 10 in isolation: IEDCR. Somoy English Desk. 2020 March 14:30.

[9]. https://en.somoynews.tv/6128/news/2314-inquarantine-10-in-isolation-IEDCR

[10]. 3 more Covid-19 patients detected in Bangladesh; all of same family: IEDCR. Somoy English Desk. 2020 March 13:00.

https://en.somoynews.tv/6161/news/3-more-Covid-19patients-detected-in-Bangladesh-all-of-same-familyIEDCR 
[11]. Two more Covid-19 patients detected in Bangladesh: IEDCR. Somoy English Desk. 2020 March

12:24.

https://en.somoynews.tv/6202/news/Two-more-Covid19-patients-detected-in-Bangladesh-IEDCR

[12]. Three more Covid-19 patients detected in Bangladesh: DGHS. Somoy English Desk. 2020 March 12:55.

https://en.somoynews.tv/6293/news/Three-more-

Covid-19-patients-detected-in-Bangladesh-DGHS

[13]. Bangladesh reports another coronavirus death.

Somoy English Desk. 2020 March 14:31.

https://en.somoynews.tv/6364/news/Bangladesh-

reports-another-coronavirus-death
[14]. 4 including 2 physicians test positive for Covid19. Dhaka Tribune. 2020 March 11:27. Available at: https://www.dhakatribune.com/bangladesh/2020/03/2

7/coronavirus-4-more-tested-positive-in-bangladeshtotal-infected-48

[15]. Bangladesh reports first coronavirus death. United News of Bangladesh. 2020 March 3:45. Available

at:

https://unb.com.bd/category/Bangladesh/bangladeshreports-first-coronavirus-dea. 